\title{
A profile of Injury in Fiji: findings from a population-based injury surveillance system (TRIP-10)
}

Iris Wainiqolo ${ }^{1 *}$, Berlin Kafoa ${ }^{1}$, Bridget Kool ${ }^{2}$, Josephine Herman ${ }^{2}$, Eddie McCaig ${ }^{1}$ and Shanthi Ameratunga ${ }^{2}$

\begin{abstract}
Background: Over 90\% of injury deaths occur in low-and middle-income countries. However, the epidemiological profile of injuries in Pacific Islands has received little attention. We used a population-based-trauma registry to investigate the characteristics of all injuries in Viti Levu, Fiji.

Method: The Fiji Injury Surveillance in Hospitals (FISH) database prospectively collected data on all injury-related deaths and primary admissions to hospital ( $\geq 12$ hours stay) in Viti Levu during 12 months commencing October 2005.

Results: The 2167 injury-related deaths and hospitalisations corresponded to an annual incidence rate of 333 per 100,000 , with males accounting for twice as many cases as females. Almost $80 \%$ of injuries involved people aged less than 45 years, and $74 \%$ were deemed unintentional. There were 244 fatalities (71\% died before admission) and 1994 hospitalisations corresponding to crude annual rates of 37.5 per 100,000 and 306 per 100,000 respectively. The leading cause of fatal injury was road traffic injury (29\%) and the equivalent for injury admissions was falls (30\%). The commonest type of injury resulting in death and admission to hospital was asphyxia and fractures respectively. Alcohol use was documented as a contributing factor in 13\% of deaths and 12\% of admissions. In general, indigenous Fijians had higher rates of injury admission, especially for interpersonal violence, while those of Indian ethnicity had higher rates of fatality, especially from suicide.

Conclusions: Injury is an important public health problem that disproportionately affects young males in Fiji, with a high proportion of deaths prior to hospital presentation. This study highlights key areas requiring priority attention to reduce the burden of potentially life-threatening injuries in Fiji.
\end{abstract}

Keywords: Injuries, Epidemiology, Injury surveillance, Fiji

\section{Background}

Injuries are a neglected public health problem in developing countries, with over $90 \%$ of the world's injury deaths occurring in low-and middle-income countries (LMIC) [1,2]. The financial demands associated with injuries pose particular difficulties for low-income families contributing to the 'injury poverty trap' [3-6].

Reliable epidemiological information is vital to guide the development of targeted injury prevention policies and strategies [7]. While some LMICs have established

\footnotetext{
* Correspondence: iris.wainiqolo@fnu.ac.fj

${ }^{1}$ College of Medicine, Nursing \& Health Sciences, Fiji National University, Suva, Fiji

Full list of author information is available at the end of the article
}

injury surveillance systems [8-13], most countries have difficulties implementing these due to limited resources. To assist member countries in these environments, the WHO has developed an Injury Surveillance Guideline advocating the collection of a minimum dataset [14].

Injury data from less resourced Pacific Island Countries and Territories has primarily relied on statistics in reports from government and non-government agencies responsible for health, law enforcement, transport, and social issues. Given the inadequacy of these data to inform robust national injury prevention efforts in Fiji, a prospective trauma registry was piloted and established in trauma admitting hospitals in Viti Levu, Fiji as part of the Traffic Related Injury in the Pacific (TRIP) Project

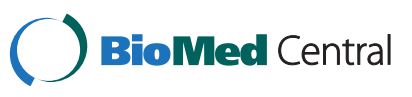


[15]. The aim of this paper is to draw on this Fiji Injury Surveillance in Hospitals (FISH) system to describe the epidemiology of all injuries and to explore differences by socio-demographic characteristics (including ethnicity) and mechanisms of injury.

\section{Methods}

This cross-sectional study used an adapted version of the WHO Injury Surveillance Guideline [14] to systematically collect information oninjury deaths and hospitalisations over a 12 month period (1 October 2005 to 30 September 2006) in all twelve trauma-admitting hospitals in Viti Levu, Fiji. At the 2007 census, approximately $70 \%$ of Fiji's resident population of 837,271 people lived in Viti Levu [16]. The injury surveillance form captured data from medical records including demographic information, injury details (place of occurrence, activity, cause, intent, nature of the principal injury, length of stay, status at discharge) and recorded information on the likely influence of alcohol and kava. Kava is a mildly narcotic traditional brew made from the root of the Piper methysticum plant [17], widely consumed by all ethnic groups in Fiji.

Data collection was carried out by research assistants and hospital nurses located at the surveillance hospitals. Quality assurance measures were implemented to ensure cases met the inclusion criteria, and data collection and coding was complete and accurate [15].

All data management and analysis was conducted using Microsoft Excel Version 12.1.7 statistical software and Epi Info Version 3.3.2. Fatal and hospitalised injury incidence rates were calculated using denominator data from the 2007 census [16].

Ethical approval for the study was obtained from the Fiji National Research Ethics Committee and the University of Auckland Ethics Committee.

\section{Results}

During the 12-month injury surveillance period, 2233 cases of injury were identified by the FISH system, 66 of whom were excluded from this analysis as they were transfers from hospitals outside of Viti Levu. The 2167 individuals who died or were admitted to hospital as a result of injury corresponded to an annual incidence of 333 per 100,000 population. Two thirds of those injured (69\%) were male, more than half $(56 \%)$ were indigenous Fijians. People aged 15 to 29 years and 30 to 44 years accounted for $35 \%$ and $23 \%$ of those injured, respectively.

\section{Injury admissions}

During the review period, 2059 people were admitted to Viti Levu hospitals as a result of injury, 65 of whom were excluded as these were transfers from hospitals outside the study region. The remaining 1994 injury admissions corresponded to a crude annual rate of 306 per 100,000 (Table 1). Of these, 71 died in hospital (case fatality rate of 3.6\%). People aged 15-29 years accounted for the highest admission rate (369 per 100,000). Males had twice the rate of admission of females. Unintentional injuries accounted for three-quarters of all injury admissions. The median length of hospital stay was 3.0 days (range 0 to 161 days).

The leading cause of injury admission was falls (30\%) followed by 'hit by a person or object' (23\%) and road traffic injury (18\%), (Table 1). Among children less than 15 years of age and people aged 45 years and older, the leading cause of injury was falls. The commonest mechanism of injury in the 15 to 44 age group was being 'hit by a person or object'.

Overall, indigenous Fijians had higher admission rates than Indians (Table 1). However, indigenous Fijians admission rates for males, and those aged <15, 15-29 and 30-44 years were higher than the corresponding Indian sub-groups; in contrast, the rate for indigenous Fijians aged greater than or equal to 45 years was lower than that among Indians.

The males aged 15-29 years in both ethnic groups (indigenous Fijians 619 per 100,000 and Indians 443 per $100,000)$ had the highest incidence rates, more than double the female rates. The same pattern was also observed in indigenous Fijians in the 30-44 years age group where the male rate was three times that of the indigenous Fijians female rate, (544 per 100,000 cf. 182 per 100,000).

Compared with Indians, indigenous Fijians had higher rates of admission for interpersonal violence. However, Indians had almost five times the rate of admission for self-inflicted injury. With respect to mechanism, indigenous Fijians had double the Indian rates of injury admission due to being hit by a person or object, and for cuts. In contrast, the rate of poisoning among Indians was three times higher than that among indigenous Fijians.

The principal injuries among those admitted to hospital were most commonly identified as fractures (41\%) and open wounds (20\%). Leisure or play (38\%), travelling (19\%) and being 'in a conflict situation' (18\%) were common activities at the time of injury. Almost half the hospitalised injuries (47\%) occurred in the home environment, and $21 \%$ occurred on the road.

Alcohol and kava use prior to the injury was documented in $12 \%$ and $3 \%$ of injury admissions, respectively, and the use of both substances together was documented in 21 cases. In $12 \%$ of cases, the use of alcohol was not recorded.

\section{Injury deaths}

There were 246 injury deaths identified in the FISH database, two of whom were excluded because they were transfers from hospitals outside of Viti Levu. Of the 
Table 1 Injury admissions to hospital by gender, age group, ethnicity, and mechanism in Viti Levu, Fiji, October 2005September 2006

\begin{tabular}{|c|c|c|c|c|c|c|}
\hline Variable & Overall § n (\%) & Overall rate* $(95 \% \mathrm{Cl})$ & Fijian n (\%) & Fijian rate $(95 \% \mathrm{Cl})$ & Indian, n (\%) & Indian rate $(95 \% \mathrm{Cl})$ \\
\hline Total & 1994 & $306.5(293.0,319.9)$ & 1133 & $320.2(301.5,338.8)$ & 756 & $290.8(270.0,311.5)$ \\
\hline \multicolumn{7}{|l|}{ Gender } \\
\hline Male & 1373(68.9) & $415.6(393.6,437.6)$ & $808(71.3)$ & $452.3(421.1,483.5)$ & $494(65.3)$ & $372.0(339.2,404.8)$ \\
\hline Female & $621(31.1)$ & $193.9(178.7,209.2)$ & $325(28.7)$ & $185.4(165.3,205.6)$ & $262(34.7)$ & $206.0(181.0,230.9)$ \\
\hline \multicolumn{7}{|l|}{ Age group } \\
\hline $0-14$ years & $451(2.6)$ & $246.8(224.0,269.5)$ & $311(27.4)$ & $274.8(244.3,305.4)$ & $123(16.3)$ & $207.3(170.6,243.9)$ \\
\hline $15-29$ years & $694(34.8)$ & $368.6(341.2,396.0)$ & $413(36.5)$ & $408.4(369.0,447.8)$ & $247(32.7)$ & $321.4(281.3,361.5)$ \\
\hline $30-44$ years & $442(22.2)$ & $321.1(291.2,351.0)$ & $259(22.8)$ & $361.3(317.3,405.3)$ & $159(21.0)$ & $274.4(231.7,317.0)$ \\
\hline$\geq 45$ years & $407(20.4)$ & $286.8(258.9,314.6)$ & $150(13.2)$ & $220.9(185.5,256.2)$ & $227(30.0)$ & $344.7(299.8,389.5)$ \\
\hline \multicolumn{7}{|l|}{ Mechanism of injury } \\
\hline Fall & $602(30.2)$ & $92.5(85.1,99.9)$ & $309(27.3)$ & $87.3(77.6,97.0)$ & $246(32.5)$ & $94.6(82.8,106.4)$ \\
\hline Hit by person or object & $466(23.4)$ & $71.6(65.1,78.1)$ & $334(29.5)$ & $94.4(84.3,104.5)$ & $108(14.3)$ & $41.5(33.7,49.4)$ \\
\hline Road traffic injury & $353(17.7)$ & $54.3(48.6,59.9)$ & $170(15.0)$ & $48.0(40.8,55.3)$ & $171(22.6)$ & $65.8(55.9,75.6)$ \\
\hline Cutting or piercing & $228(11.4)$ & $35.0(30.5,39.6)$ & $167(14.7)$ & $47.2(40.0,54.3)$ & $50(6.6)$ & $19.2(13.9,24.6)$ \\
\hline Poisoning & $169(8.5)$ & $26.0(22.1,29.9)$ & $48(4.2)$ & $13.6(9.7,17.4)$ & $117(15.5)$ & $45(36.8,53.2)$ \\
\hline Fire/heat/electricity & $109(5.5)$ & $16.8(13.6,19.9)$ & $62(5.5)$ & $17.5(13.2,21.9)$ & $45(6.0)$ & $17.3(12.3,22.4)$ \\
\hline Choking or hanging & $17(0.9)$ & $2.6(1.4,3.9)$ & $10(0.9)$ & $2.8(1.1,4.6)$ & $6(0.8)$ & $2.3(0.5,4.2)$ \\
\hline Sexual assault & $9(0.5)$ & $1.4(0.5,2.3)$ & - & - & - & - \\
\hline Near drowning & - & - & - & - & - & - \\
\hline Other & $18(0.9)$ & $2.8(1.5,4.0)$ & $13(1.1)$ & $3.7(1.7,5.7)$ & - & - \\
\hline Unknown & $19(1.0)$ & $2.9(1.6,4.2)$ & $13(1.1)$ & $3.7(1.7,5.7)$ & $5(0.7)$ & $1.9(0.2,3.6)$ \\
\hline \multicolumn{7}{|l|}{ Intent } \\
\hline Unintentional & $1493(74.9)$ & $229.5(217.8,241.1)$ & $844(74.5)$ & $238.5(222.4,254.6)$ & $568(75.1)$ & $218.5(200.5,236.4)$ \\
\hline Self-inflicted injury & $144(7.2)$ & $22.1(18.5,25.7)$ & $30(2.6)$ & $8.5(5.4,11.5)$ & $109(14.4)$ & $41.9(34.1,49.8)$ \\
\hline Interpersonal violence & $306(15.3)$ & $47(41.8,52.3)$ & $23(20.4)$ & $65.3(56.9,73.7)$ & $58(7.7)$ & $22.3(16.6,28.1)$ \\
\hline Undetermined & $51(2.5)$ & $7.8(5.7,10.0)$ & $28(2.5)$ & $7.9(5.0,10.8)$ & $21(2.8)$ & $8.1(4.6,11.5)$ \\
\hline \multicolumn{7}{|l|}{ Outcome } \\
\hline Discharged & $1923(96.4)$ & $295.6(282.3,308.8)$ & 1105 (97.5) & $312.2(293.8,330.6)$ & $715(94.6)$ & $275.0(254.8,295.1)$ \\
\hline Died while admitted & $71(3.6)$ & $10.9(8.4,13.5)$ & $28(2.5)$ & $7.9(5.0,10.8)$ & $41(5.4)$ & $15.98(10.9,20.6)$ \\
\hline \multicolumn{7}{|l|}{ Length of stay (days) } \\
\hline Total & 13,515 & & 7463 & & 5371 & \\
\hline Mean & 6.8 & & 6.6 & & 7.1 & \\
\hline Median & $3(0-161)$ & & $3(0-107)$ & & $3(0-161)$ & \\
\hline
\end{tabular}

Source:Fiji Bureau of Statistics 2007 census data[16]; * Rate per 100,000; § 'Other' ethnic group is included in the overall count and rate calculation; - Cells with values less than 5 have been omitted.

remaining 244 fatalities (crude annual rate of 37.5 per $100,000)$, most (71\%) occurred before admission (Table 2 ). Nearly two thirds (64\%) of injury deaths were among people aged 15 to 44 years, and unintentional events accounted for $57 \%$ of all injury deaths.

The leading cause of injury-related deaths was road traffic injury (29\%) followed by 'choking or hanging' (25\%) and drowning (12\%). Road traffic injury was the leading cause of injury death in all age groups except the 15-29 age groups where 'choking or hanging' was more common.
In contrast to admission rates, Indians had double the fatality rate of indigenous Fijians both in males and females (Table 2). Similar to admissions, Indians had higher mortality rates due to self-inflicted injury, but mortality rate due to interpersonal violence was close to that registered among indigenous Fijians.

'Choking or hanging' (35\%), road traffic injury (27\%), and 'fire, heat or electricity' related injuries (13\%) were the commonest causes of injury deaths among Indians. Road traffic injury (34\%), drowning (18\%) and 'choking or 
Table 2 Injury deaths by gender, age group, ethnicity, and mechanism in Viti Levu, Fiji, October 2005-September 2006

\begin{tabular}{|c|c|c|c|c|c|c|}
\hline Variable & Overall § n (\%) & Overall rate* $(95 \% \mathrm{Cl})$ & Fijian n (\%) & Fijian rate $(95 \% \mathrm{Cl})$ & Indian n (\%) & Indian rate $(95 \% \mathrm{Cl})$ \\
\hline Total & 244 & $37.5(32.8,42.2)$ & 98 & $27.7(22.2,33.2)$ & 129 & $50(41.1,58.2)$ \\
\hline \multicolumn{7}{|l|}{ Gender } \\
\hline Male & $156(63.9)$ & $47.2(39.8,54.6)$ & $64(65.3)$ & $35.8(27.0,44.6)$ & $80(62.0)$ & $60(47.0,73.4)$ \\
\hline Female & $88(36.1)$ & $27.5(21.7,33.2)$ & $34(34.7)$ & $19.4(12.9,25.9)$ & $49(38.0)$ & $39(27.7,49.3)$ \\
\hline \multicolumn{7}{|l|}{ Age group } \\
\hline $0-14$ years & $28(11.5)$ & $15.3(9.6,21)$ & $24(24.5)$ & $21.2(12.7,29.7)$ & - & - \\
\hline $15-29$ years & $95(38.9)$ & $50.5(40.3,60.6)$ & $30(30.6)$ & $29.7(19.0,40.3)$ & $60(46.5)$ & $78(58.3,97.8)$ \\
\hline $30-44$ years & $61(25.0)$ & $44.3(33.2,55.4)$ & $28(28.6)$ & $39.1(24.6,53.5)$ & $27(20.9)$ & $47(29.0,64.2)$ \\
\hline$\geq 45$ years & $60(24.6)$ & $42.3(31.6,53.0)$ & $16(16.3)$ & $23.6(12.0,35.1)$ & $38(29.5)$ & $58(39.4,76.0)$ \\
\hline \multicolumn{7}{|l|}{ Mechanism of injury } \\
\hline Road traffic injury & $70(28.7)$ & $10.8(8.3,13.3)$ & $33(33.7)$ & $9.3(6.1,12.5)$ & $35(27.1)$ & $13(9.0,17.9)$ \\
\hline Choking or hanging & $61(25.0)$ & $9.4(7,11.7)$ & $13(13.3)$ & $3.7(1.7,5.7)$ & $45(34.9)$ & $17(12.3,22.4)$ \\
\hline Drowning & $28(11.5)$ & $4.3(2.7,5.9)$ & $18(18.4)$ & $5.1(2.7,7.4)$ & - & - \\
\hline Fire/heat/electricity & $22(9.0)$ & $3.4(2.0,4.8)$ & - & - & $17(13.2)$ & $7(3.4,9.6)$ \\
\hline Poisoning & $17(7.0)$ & $2.6(1.4,3.9)$ & - & - & $13(10.1)$ & $5(2.3-7.7)$ \\
\hline Fall & $16(6.6)$ & $2.5(1.3,3.7)$ & $9(9.2)$ & $2.5(0.9,4.2)$ & $6(4.7)$ & $2(0.5,4.2)$ \\
\hline Hit by person or object & $12(4.9)$ & $1.8(0.8,2.9)$ & $8(8.2)$ & $2.3(0.7,3.8)$ & - & - \\
\hline Cutting or piercing & $11(4.5)$ & $1.7(0.7,2.7)$ & $5(5.1)$ & $1.4(0.2,2.7)$ & $5(3.9)$ & $2(0.2,3.6)$ \\
\hline Other & $7(2.9)$ & $1.1(0.4,1.9)$ & $6(6.1)$ & $1.7(0.3,3.1)$ & - & - \\
\hline \multicolumn{7}{|l|}{ Intent } \\
\hline Unintentional & $138(56.5)$ & $21.2(17.7,24.7)$ & $70(71.4)$ & $19.8(15.1,24.4)$ & $57(44.2)$ & $21.9(16.2,27.6)$ \\
\hline Self-inflicted injury & $78(32.0)$ & $12.0(9.3,14.6)$ & $9(9.2)$ & $2.5(0.9,4.2)$ & $64(49.6)$ & $24.6(18.6,30.6)$ \\
\hline Interpersonal violence & $19(7.8)$ & $2.9(1.6,4.2)$ & $13(13.3)$ & $3.7(1.7,5.7)$ & $6(4.7)$ & $2.3(0.5,4.2)$ \\
\hline Undetermined & $9(3.7)$ & $1.4(0.5,2.3)$ & $6(6.1)$ & $1.7(0.3,3.1)$ & - & - \\
\hline \multicolumn{7}{|l|}{ Timing of death } \\
\hline Prior to admission & $173(70.9)$ & $26.6(22.6,30.6)$ & $70(71.4)$ & $19.8(15.1,24.4)$ & $88(68.2)$ & $34(26.7,40.9)$ \\
\hline During admission & $71(29.1)$ & $10.9(8.4,13.5)$ & $28(28.6)$ & $7.9(5.0,10.8)$ & $41(31.8)$ & $16(10.9,20.6)$ \\
\hline
\end{tabular}

Source: Fiji Bureau of Statistics 2007 census data [16]; * Rate per 100,000; § 'Other' ethnic group is included in the overall count and rate calculation; - Cells with values less than 5 have been omitted.

hanging' (13\%) were the commonest in indigenous Fijians. 'Choking or hanging' and 'fire, heat or electricity'-related deaths were higher among Indians compared to indigenous Fijians.

Injury deaths were most commonly attributed to asphyxia (36\%) and head injury (20\%). The context of injury deaths were most often defined as a 'conflict situation' (32\%), or while travelling (26\%). Close to half of the injury deaths (48\%) occurred at home.

Of the 244 injury deaths, $13 \%$ were considered to have involved alcohol use, (17\% males cf. $6 \%$ females). Alcohol use was recorded as 'unknown' among 28 females and 55 males. Kava use was suspected or confirmed in $2 \%$ of deaths.

\section{Discussion}

This analysis of fatal and hospitalized injury in Viti Levu, Fiji, indicates that substantial burden of acute injury involving males and people in the economicallyproductive ages of 15 to 44 years. The most common locations of injury were the home and road. Nearly threequarters of injury events were unintentional with road traffic injuries and falls comprising the leading causes of injury death and admissions respectively. 'Hanging or choking' and assault were the leading causes of intentional injury death and hospitalisation. Most injury deaths occurred before admission. Indigenous Fijians had higher rates of injury admission, more than half of which were due to being 'hit by a person or object' and falls. People of Indian ethnicity had higher rates of fatality, especially from suicide. While alcohol use was implicated in injury deaths and hospital admissions, the contribution of substances, in general, is underestimated in the absence of systematic enquiry and objective measures.

The population-based Fiji Injury Surveillance in Hospitals (FISH) system has demonstrated that it is feasible 
to obtain a comprehensive policy-relevant profile of injury using a simple data collection form in lowresourced Pacific nations. The hospitals involved in this study were located throughout the main island, and covered urban and rural environments.

The findings must also be interpreted in light of several limitations. While the pilot phase of this study attempted to ensure mechanisms of particular relevance for this context were captured, the efficiency of the simple data collection form also required compromises with regard to the specificity of information. For example, some broad categories of injuries (such as fire, heat or electricity) limited our ability to look at each group separately.

The principal injury captured by the FISH system was the one deemed the most serious in terms of threat to life. However, misclassification of this variable is likely in the absence of a formal injury severity coding system. As the study was restricted to deaths and hospital admissions, injuries that are less severe but could result in disability were not identified.

The findings in relation to the predominance of males and road traffic injuries are consistent with trends seen in other developing countries $[10,12,13,18]$. While data on the specific types of road users was not available in this study, data from other LMICs report pedestrians, bicyclists, and motorcyclists as the most vulnerable groups [12,19-21].

More than two thirds of the injury deaths identified in this study, occurred before arrival in hospital - a high proportion relative to other developing countries [22,23]. Mock et al. in their analysis of mortality trends in three nations with different economic levels showed that prehospital deaths declined with increased economic level [22]. The majority of pre-hospital care in Fiji is provided by ambulance services aligned to regional hospitals. The findings indicate the need to review the effectiveness of emergency response services including training of personnel, and transfer times to definitive care.

Ethnic-specific differences by intent showed consistent patterns for injury deaths and admissions. Indigenous Fijians had higher rates of interpersonal violence while Indians had higher rates of self-inflicted harm. The latter finding is consistent with findings from previous research in Fiji [24], India [25,26], and other LMICs.

The suspicion of alcohol use prior to injury, particularly among males aged $15-44$, is consistent with the international literature [27]. However, both alcohol and kava use as contributing factors in this study are likely to have been under-estimated in a country where blood alcohol testing is not routinely done unless requested by Police, and kava use is common among people, often in combination with alcohol [28].

The absence of an objective measure for injury severity was a limitation of the FISH system. While scoring methods applied in high-income countries may be difficult to implement due to available resources and training, the use or adaptation of a score such as the Kampala Trauma Score [29] could be a useful adjunct to data collected on trauma patients in Fiji. This would provide the opportunity to risk adjust when considering changes in the profiles of injury over time, the impact of interventions, and the quality of pre-hospital and inpatient trauma care.

Previous publications using injury surveillance systems established in Thailand [30], Ethiopia [12], Jamaica [8], South Africa [31], and Nicaragua [13] have identified some limitations in data collection similar to our study. Particular issues identified include: challenges to assuring data quality, inadequate human resources, incomplete and inaccurate coding, and a lack of a surveillance culture. Collectively, these studies also reveal the importance of integrating data collection into patient registration systems as key to the success of surveillance systems.

Limited resources can challenge the establishment of robust public health surveillance systems in low resourced countries [32]. However, attention to characteristics that support the reliability and sustainability of a surveillance system [33] would provide the opportunity to monitor future trends in injury in Fiji, and evaluate the impact of preventive interventions. Mitchell et al. identify three priority areas that are especially pertinent to injury surveillance systems [34]. These include (1) 'data quality' - to ensure the information collected is complete, representative, valid and reliable; (2) the operational capacity - to ensure that the surveillance system has a clear purpose and objectives, case definitions, data collection process while also being simple, flexible and responsive to change; and (3) 'practical capability'-to ensure the accessibility, acceptability and usefulness of data, incorporating the necessary resource allocation, communication support, and training.

As a component of a wider research project, the FISH system was designed to generate a population-based profile of acute injury events in Viti Levu over 12 months. The project demonstrated that a simple yet efficient, standardized data collection system could be effectively implemented in Viti Levu. The experience gained with FISH is timely given the proposed national accident and injury surveillance system identified in the Fiji NonCommunicable Disease Strategic Plan (2010 - 14) [35]. Of relevance, Fiji has recently launched a national Health Information policy [36] modeled on the Health Metrics Network (HMN) framework [37]. The core objective of this policy is to provide timely and quality information to support health service planning. The findings of the present study alongside these national initiatives provide the impetus to design, implement and evaluate a comprehensive injury control strategy in Fiji. The strategies 
required include giving priority attention to preventing road traffic injury, falls, intentional injuries and alcoholrelated injuries, as well as attention to improving outcomes across the injury continuum, particularly including effective pre-hospital care. The study also identifies the need to examine the context-specific risk and protective factors that can address the burden of injuries in less-resourced Pacific Island nations.

\section{Conclusions}

Injury is an important public health problem that disproportionately affects young males in Viti Levu, Fiji. A high proportion of injury-related deaths occur prior to hospital presentation. This study highlights road traffic injury, falls, intentional injuries and alcohol-related injuries as key areas requiring priority attention to reduce the burden of potentially life-threatening injuries. With local initiatives to develop a national injury prevention strategy and enhance health information systems, there is a critical opportunity to address injury control as a major public health program in countries with limited resources in the Pacific.

\section{Competing interests}

The authors declare that they have no competing interests.

\section{Authors' contributions}

IW helped design the study, was one of two research managers supervising the conduct of the study, and wrote the initial draft of the manuscript. BKafoa helped design the study, was one of two research managers supervising the conduct of the study, and contributed to the interpretation of the study findings. BKool contributed to the analysis and interpretation of the study results, and assisted with preparation of the manuscript. JH assisted with the statistical analysis of the study results and with the development of the manuscript. EM is a co-principal investigator of the project; he contributed to the interpretation of the study findings, and critically revising the draft manuscript. SA is the project director and a coprincipal investigator obtaining funding for the study, contributed to the design and supervised the implementation and analysis of the study, interpretation of findings, and critically revising the draft manuscript for important intellectual content. All authors read and approved the final manuscript.

\section{Acknowledgements}

This study was funded by an International Collaborative Research Grant awarded by the Wellcome Trust (UK) and the Health Research Council of New Zealand.

The authors gratefully acknowledge the support of the Permanent Secretary of Health, Dr. Lepani Waqatakirewa and the Fiji Ministry of Health staff, doctors and nurses at national, divisional and sub divisional levels, the pathologists at Lautoka and CWM hospitals, the TRIP research team including Professors Sitaleki Finau and Rod Jackson, Dr Robyn Mclntyre, Asilika Naisaki, Mabel Taoi, Ravi Reddy, Ramneek Gounder, Litia Vuniduvu, and Nola Vanualailai, and biostatistical advice from Elizabeth Robinson.

\section{Author details}

${ }^{1}$ College of Medicine, Nursing \& Health Sciences, Fiji National University, Suva, Fiji. ${ }^{2}$ Section of Epidemiology and Biostatistics, School of Population health, University of Auckland, Private Bag, Auckland 92019, New Zealand.

Received: 30 August 2012 Accepted: 7 December 2012

Published: 12 December 2012

\section{References}

1. Peden MMK, Sharma G: The injury chart book: a graphical overview of the global burden of injuries. Geneva: World Health Organization; 2002.

2. Gosselin RA, Spiegel DA, Coughlin R, Zirkle LG: Injuries: the neglected burden in developing countries. Bull World Health Org 2009, 87.

3. Ameratunga S, Officer A, Temple B, Tin ST: Rehabilitation of the injured child. Bull World Health Org 2009, 87:237-238.

4. Arokiasamy J, R K: Some epidemiological aspects and economic costs of injuries in Malaysia. Asia Pac J Public Health 1994, 7(1):16-20.

5. Thanh NX: The injury poverty trap in rural Vietnam: Causes, consequences and possible solutions. Department of Public Health and Clinical Medicine: Umeå University, Epidemiology and Public Health Sciences; 2005.

6. Thanh NX, Hang HM, Chuc NTK, Rudholm N, Emmelin A, Lindholm L: Does "the injury poverty trap" exist?: A longitudinal study in Bavi, Vietnam. Health Policy 2006, 78(2-3):249-257.

7. Schopper D, Lormand J, Waxweiler R: Developing policies to prevent injuries and violence: guidelines for policy-makers and planners. Geneva: World Health Organization; 2006.

8. Arscott-Mills S, Gordon G, McDonald A, Holder Y, Ward E: A profile of injuries in Jamaica. Inj Control Saf Promot 2002, 9(4):227-234.

9. Kobusingye OC, Guwatudde D, Owor G, Lett RR: Citywide trauma experience in Kampala, Uganda: a call for intervention. Inj Prev 2002, 8(2):133-136.

10. Kobusingye OC, Lett RR: Hospital-Based Trauma Registries in Uganda. J Trauma 2000, 48(3):498-502.

11. Rahman F, Andersson R, Svanstrom L: Potential of using existing injury information for injury surveillance at the local level in developing countries: experiences from Bangladesh. Public Health 2000, 114(2):133-136.

12. Taye M, Munie T: Trauma registry in Tikur Anbessa Hospital, Addis Ababa, Ethiopia. Ethiop Med J 2003, 41(3):221-226.

13. Tercero FAR, Rocha J, Castro N, Svanstrom L: On the epidemiology of injury in developing countries: A one-year emergency room-based surveillance experience from Leon,Nicaragua. Int J Consumer Product Safety 1999, 6(1):33-42

14. Holder YPM, Krug E, et al: (Eds): Injury surveillance guidelines. Geneva: World Health Organization; 2001.

15. Wainiqolo I, Kafoa B, McCaig E, Kool B, Mclntyre R, Ameratunga S: Development and piloting of the Fiji Injury Surveillance in Hospitals System (TRIP Project-1). Injury 2011, in press.

16. Fiji Bureau of Statistics: Census data. 2007. Accessed 17/06/11. http://www.fijigov.fj.

17. Yadhu NS: Kava: an overview. J Ethnopharmacol 1992, 37(1):13-45.

18. Rahman F, Ali Y, Andersson R, Svanstrom L: Epidemiology of injury: Results from injury registration at a district level hospital in Bangladesh - implications for prevention in low-income countries. Inj Control Saf Promot 2001, 8(1):29-36.

19. Ameratunga S, Hijar M, Norton R: Road-traffic injuries: confronting disparities to address a global-health problem. Lancet 2006, 367 (9521):1533-1540.

20. Sharma BR: Road traffic injuries: A major global public health crisis. Public Health 2008, 122(12):1399-1406.

21. Odero W, Garner P, Zwi A: Road traffic injuries in developing countries: a comprehensive review of epidemiological studies. Trop Med Int Health 1997, 2(5):445-460.

22. Mock CN, Jurkovich GJ, Nii-Amon-Kotei D, Arreola-Risa C, Maier RV: Trauma mortality patterns in three nations at different economic levels: implications for global trauma system development. The Journal of Trauma and Acute Care Surgery 1998, 44(5):804-814.

23. Montazeri A: Road-traffic-related mortality in Iran: a descriptive study. Public Health 2004, 118(2):110-113.

24. Morris P, Maniam T: Suicide in Fiji: a review of the literature. Asia Pac J Public Health 2000, 12(1):46-49.

25. Adityanjee D: Suicide attempts and suicides in India. Int J Soc Psychiatry 1986, 32(2):64-73.

26. Eddleston M, Konradsen F: Commentary: Time for a re-assessment of the incidence of intentional and unintentional injury in India and South East Asia. Int J Epidemiol 2007, 36(1):208-211.

27. Cherpitel CJ: Injury and the role of alcohol: county-wide emergency room data. Alcohol Clin Exp Res 1994, 18(3):679-684. 
28. Cornelius M, Decourten M, Pryor J, Saketa S, Waqanivalu T, Laqeretabua A, Chung E: Fiji Non-communicable disease (NCD) STEPS Survey 2002. Suva: Ministry of Health; 2004.

29. MacLeod JA, Kobusingye O, Frost C, Lett R, Kirya F, Shulman C: A Comparison of the Kampala Trauma Score (KTS) with the Revised Trauma Score (RTS), Injury Severity Score (ISS) and the TRISS Method in a Ugandan Trauma Registry. European Journal of Trauma 2003, 29(6):392-398.

30. Santikarn C, Punyaratanabandhu P, Podhipak A, Rukronayut K, DSe a: The establishment of injury surveillance in Thailand. Int $J$ Consumer \& Product Safety 1999, 6(3):133-143

31. Schuurman N, Cinnamon J, Matzopoulos R, Fawcett V, Nicol A, Hameed SM: Collecting injury surveillance data in low- and middle-income countries: The Cape Town Trauma Registry pilot. Glob Public Health 2011, 6(8):874-889.

32. St Louis M: Global Health Surveillance. MMWR 2012, 61:15-18.

33. Hall IH, Correa A, Yoon PW, Braden CR: Lexicon, definitions, and conceptual framework for public health surveillance. MMWR 2012, 61:10-24.

34. Mitchell R, Williamson A, O'Connor R: The development of an evaluation framework for injury surveillance systems. BMC Public Health 2009, 9(1):260.

35. Ministry of Health F: Non-Communicable Diseases Prevention and Control Strategic Plan 2010-2014. In Edited by Health P. Suva: Ministry of Health; 2010.

36. Ministry of Health F: Health Information Policy 2011. Suva: Government Printery; 2011.

37. WHO: Health Metrics Network - Framework and Standards for Country Health Information Systems. Geneva: WHO; 2008.

doi:10.1186/1471-2458-12-1074

Cite this article as: Wainiqolo et al:: A profile of Injury in Fiji: findings

from a population-based injury surveillance system (TRIP-10). BMC Public Health 2012 12:1074.

\section{Submit your next manuscript to BioMed Central and take full advantage of:}

- Convenient online submission

- Thorough peer review

- No space constraints or color figure charges

- Immediate publication on acceptance

- Inclusion in PubMed, CAS, Scopus and Google Scholar

- Research which is freely available for redistribution 